\title{
ДИАГНОСТИЧЕСКАЯ ЗНАЧИМОСТЬ ПОКАЗАТЕЛЕЙ ГОРМОНАЛЬНОЙ АКТИВНОСТИ ЖИРОВОЙ ТКАНИ У ПОДРОСТКОВ С РАЗЛИЧНОЙ СТЕПЕНЬЮ ОЖИРЕНИЯ
}

\author{
Олейник О.А., Самойлова Ю.Г., Саган Е.В., Денисов Н.С., Басарева Н.И., Подчиненова Д.В.
}

ФГБОУ ВО Сибирский государственный медицинский университет, г.Томск

Цель: установить взаимосвязь уровней лептина, резистина и иризина в зависимости от SDS ИТМ у детей и подростков с различной степенью ожирения

Материалы и методы: Обследованы 40 подростков (средний возраст 12,1士1,2) (19 мальчиков и 21 девочка) с избыточной массой тела и ожирением различной степени, определенной в зависимости от SDS ИТМ согласно действующей классификации ВОЗ. Контрольную группу составили 26 подростков (средний возраст $12,4 \pm 1,1$ ) с равным количеством мальчиков и девочек с нормальной массой тела. Показатели гормональной активности жировой ткани (уровень лептина, резистина и иризина) определялся в сыворотке крови методом ИФА с использованием лабораторных наборов фирмы «Сlaud clone corporation» (США) на анализаторе иммуноферментных реакций "Униплан" (Россия). Статистическая обработка полученных результатов осуществлялась с помощью программы IBM SPSS Statistics 17.0. Проверка на нормальность проводилась с помощью критерия Шапиро-Вилка. Статистические различия выборок, не подчиняющихся нормальному закону, устанавливали с помощью непараметрических критериев для независимых - Краскела-Уоллиса, Манна-Уитни (Uтест). Параметры распределений представляли в виде медианы $(\mathrm{Me})$ и межквартильного интервала (Q1:Q3). Выбранный статистический уровень значимости $\mathrm{p}<0,05$.

Результаты: Учитывая, что статистических отличий в зависимости от пола ни по одному из показателей выявлено не было, дальнейший анализ полученных данных проводился без учета гендерной принадлежности. Уровень лептина статистически достоверно по сравнению с контролем $(13,62(8,51 ; 26,0)$ нг/мл) повышался в зависимости от степени ожирения и составил у пациентов с первой, второй и третьей степенями ожирения 7,99 (6,15;8,23), 8,76 (7,68;19,37) и 25,08 $(19,21 ; 23,52)$ нг/мл соответственно. Отмечалось так же увеличение показателей концентрации резистина в сыворотке крови по мере нарастания степени ожирения, которые составили $1,06(0,51 ; 1,94), 2,15$ $(1,48 ; 4,21), 2,80(1,683 ; 7,05)$ и $5,43(1,56 ; 27,99)$ нг/мл в подгруппах подростков с избыточной массой тела и с первой по третью степень ожирения соответственно, но при этом показатели контрольной группы - 4,87 $(0,71 ; 6,54)$ нг/мл не имели статистически достоверных отличий. Уровень иризина 7,30 $(7,04 ; 7,64)$ нг/мл не имел достоверных отличий в подгруппах с различной степенью ожирения в сравнении с контролем $7,17(7,0 ; 7,45)$ нг/мл.

Выводы: На основании проведенного исследования выявлена зависимость показателей гормональной активности жировой ткани (лептин и резистин) от степени ожирения у подростков, при этом уровень иризин такой зависимости не показал. 